\title{
Enhanced Control of Attention by Stimulating Mesolimbic-Corticopetal Cholinergic Circuitry
}

\author{
Megan St. Peters, ${ }^{1}$ Elise Demeter, ${ }^{1,2}$ Cindy Lustig, ${ }^{1,2}$ John P. Bruno, ${ }^{3}$ and Martin Sarter ${ }^{1,2}$ \\ ${ }^{1}$ Department of Psychology, ${ }^{2}$ Neuroscience Program, University of Michigan, Ann Arbor, Michigan 48109-8862, and ${ }^{3}$ Department of Psychology, Ohio State \\ University, Columbus, Ohio 43210
}

\begin{abstract}
Sustaining and recovering attentional performance requires interactions between the brain's motivation and attention systems. The first experiment demonstrated that in rats performing a sustained attention task (SAT), presentation of a distractor (dSAT) augmented performance-associated increases in cholinergic neurotransmission in prefrontal cortex. Because stimulation of NMDA receptors in the shell of the nucleus accumbens activates PFC cholinergic neurotransmission, a second experiment demonstrated that bilateral infusions of NMDA into the NAc shell, but not core, improved dSAT performance to levels observed in the absence of a distractor. A third experiment demonstrated that removal of prefrontal or posterior parietal cholinergic inputs, by intracortical infusions of the cholinotoxin 192 IgG-saporin, attenuated the beneficial effects of NMDA on dSAT performance. Mesolimbic activation of cholinergic projections to the cortex benefits the cognitive control of attentional performance by enhancing the detection of cues and the filtering of distractors.
\end{abstract}

\section{Introduction}

Motivation interacts with attention to preserve performance under challenging conditions, influencing the engagement of control mechanisms that maintain goal representations, modulate the processing of relevant and irrelevant stimuli, and modify ongoing performance (Christakou et al., 2004; Sarter et al., 2006; Engelmann and Pessoa, 2007; Pezze et al., 2007; Sabatinelli et al., 2007; Gruber et al., 2009; Daniel and Pollmann, 2010; Savine and Braver, 2010). Motivational-incentive processing involves mesolimbic circuitry, particularly the dopaminergic midbrain and the nucleus accumbens (Knutson et al., 2001; Adcock et al., 2006; Cooper and Knutson, 2008). Top-down control relies on frontoparietal cortical regions (Wager et al., 2004; Lim et al., 2010; Ptak and Schnider, 2010). However, the precise circuitry underlying motivation's modulation of attention remains largely undefined. Here, we show that interactions between the NAc and the basal forebrain corticopetal cholinergic projection system are essential components of the circuitry involved in the motivated recruitment of attention.

Prefrontal glutamatergic projections to the NAc integrate topdown signals for the organization of goal-directed behavior (Mogenson et al., 1980; Gruber et al., 2009). In turn, NAc GABAergic efferent projections contact basal forebrain cholinergic neurons

Received April 15, 2011; revised May 23, 2011; accepted May 23, 2011.

Author contributions: C.L., J.P.B., and M.S. designed research; M.S.P. and E.D. performed research; M.S.P. and E.D. analyzed data; M.S.P., C.L., J.P.B., and M.S. wrote the paper.

This research was supported by United States Public Health Service Grants MH057436 (J.P.B., M.S.) and MH086530 (M.S., C.L.) and National Science Foundation Grant 0726285 (C.L.). M.S.P. was supported by a National Institute of Mental Health Postdoctoral Fellowship (F32 MH088084) and E.D. by a National Science Foundation Graduate Research Fellowship.

Correspondence should be addressed to Dr. Martin Sarter, Department of Psychology, University of Michigan, 530 Church Street, 4032 East Hall, Ann Arbor, Ml 48109-8862. E-mail: msarter@umich.edu.

DOI:10.1523/JNEUROSCI.1902-11.2011

Copyright $\odot 2011$ the authors $\quad 0270-6474 / 11 / 319760-12 \$ 15.00 / 0$
(Záborszky et al., 1986; Ingham et al., 1988; Záborszky and Cullinan, 1992). Modulation of GABAergic neurotransmission in the basal forebrain influences activated levels of cortical cholinergic neurotransmission and attentional performance (Holley et al., 1995). Although the precise circuitry linking the NAc to cholinergic projections is unclear, stimulation of ionotropic glutamate receptors in the rostrocaudal shell of the NAc, which enhances motivation (Faure et al., 2010), robustly increases prefrontal cholinergic neurotransmission. Furthermore, these increases are positively modulated by NAc dopamine D1 receptor activation (Zmarowski et al., 2005, 2007; Alexander et al., 2009). Furthermore, disruption of NAc neurotransmission attenuated cortical cholinergic neurotransmission in a behavioral test that combined attentional demands and motivational conflicts (Neigh et al., 2004). The attention task used in the present experiments has been instrumental in documenting that cholinergic modulation of frontoparietal cortex is essential for attentional performance, especially under challenging conditions (McGaughy and Sarter, 1995; Gill et al., 2000; McGaughy et al., 2002; Broussard et al., 2006, 2009). The basic circuitry underlying task performance and response to challenge appears to be fairly well conserved across species (Demeter et al., 2011).

In this study, we examined whether stimulation of NAc-cholinergic interactions benefits the attentional performance under taxing conditions. We first investigated how a distractor manipulation that is hypothesized to increase demands on control of attention (Demeter et al., 2008, 2011; Nuechterlein et al., 2009) affected performance-mediating increases in cholinergic neurotransmission. Second, we determined whether stimulation of glutamate receptors in the NAc shell or core restores performance in the presence or absence of a distractor. Third, we tested the necessity of cholinergic projections to prefrontal and posterior parietal regions for demonstrating the enhancing effects of 
NAc stimulation. Together, our results suggest that NAc-cholinergic interactions mediate and are necessary for improving attentional performance in challenging conditions.

\section{Materials and Methods}

Subjects

Adult male Wistar rats (Harlan Laboratories), aged 3-5 months and weighing between 250 and $300 \mathrm{~g}$ at the beginning of the experiments, were used. Animals were individually housed in a temperature- $\left(23^{\circ} \mathrm{C}\right)$ and humidity-controlled (45\%) environment with a 12:12 light/dark cycle (lights on at 7:00 A.M.). Animals were handled extensively before the beginning of training and were water-deprived by restricting access for a $10 \mathrm{~min}$ period following each operant training or practice session. Water was also provided as a reward during task performance (see below). On days not tested, water access was increased to a total duration of 30 min. Food (Rodent Chow; Harlan Teklad) was available ad libitum. All procedures were conducted in adherence with protocols approved by the University Committee on Use and Care of Animals at the University of Michigan and in Association for Assessment and Accreditation of Laboratory Animal Care-accredited laboratories. For all major results, the statistical results include the degrees of freedom to indicate the number of animals per experiment and condition.

\section{Behavioral apparatus, modifications for remote intracranial infusions, task acquisition, distractor presentation, and performance criteria for tethered animals}

Behavioral training and testing took place using 12 operant chambers located inside sound-attenuating chambers (Med Associates). The chambers were equipped with an intelligence panel consisting of three panel lights $(2.8 \mathrm{~W})$, two retractable levers, and a water dispenser (40-45 $\mu \mathrm{l}$ of water per delivery). A house light $(2.8 \mathrm{~W})$ was located on the rear wall. Before and during sessions involving infusions of drugs into the nucleus accumbens (see below), animals were tested in modified operant chambers. These boxes featured a taller recessed water delivery area $(9.0 \times 5.0 \mathrm{~cm}$, height $\times$ width $)$ to allow cannulated animals to drink and an opening in the ceiling of the operant chamber and sound-attenuating chamber to allow for the syringes and infusion tubing to remain outside the chambers. This arrangement permitted remote infusions while not interfering with the animals' performance. Signal presentation, lever operation, reinforcement delivery, and data collection were controlled by a PC and Med-PC for Windows software (V 4.1.3; Med Associates).

The sustained attention task (SAT) (Fig. 1a), training procedures, and evidence in support of the validity of performance measures in terms of indicating sustained attention performance in rats and humans have been described previously (McGaughy and Sarter, 1995; Demeter et al., 2008). Briefly, animals were trained to discriminate between a signal ( $1 \mathrm{~s}$ illumination of the central panel light) and a nonsignal (no illumination) event. Two seconds following such events, the levers were extended into the chamber. On signal trials, a response on the left lever was reinforced and termed a "hit," and a response on the right lever was not reinforced and termed a "miss." On nonsignal trials, a response on the right lever was reinforced and termed a "correct rejection," and a response on the left lever was not reinforced and termed a "false alarm." Half of the animals were trained using the reverse set of rules. If no response occurred within $4 \mathrm{~s}$, the levers were retracted and an omission was recorded. Session length was set at $40 \mathrm{~min}$ to allow for post hoc analysis of performance over five blocks ( 8 min per block) (Fig. $1 a-c$ ). The final version of the task was identical to the previous training stage except that three signal durations were used (500, 50, and $25 \mathrm{~ms}$ ), and the house light was illuminated throughout the session. This key final modification required the animals to constrain their behavior and, presumably, to maintain persistent attention to the intelligence panel to monitor the signal source. Criterion performance at this stage was defined as $>70 \%$ hits to $500 \mathrm{~ms}$ signals, $>70 \%$ correct rejections, and $<20 \%$ omissions for seven consecutive sessions.

After attaining criterion performance, additional daily training sessions were conducted in the operant chambers modified for allowing remote intracranial infusions. In addition, procedures designed to foster habituation to the infusion procedures were initiated. Rats were placed in these chambers 5 min before task onset. During subsequent infusion sessions, this time period corresponded with a 5 min acclimation period after insertion of infusion cannula. House lights remained illuminated during both the pretask and task periods. When tethered, final criterion performance was lowered to account for a modest decrease in performance when tethered, defined as $>65 \%$ hits to $500 \mathrm{~ms}$ signals, $>65 \%$ correct rejections, and $<20 \%$ omissions for three consecutive sessions. After attaining stable performance in the final stage of the sustained attention task in the modified chambers for at least $3 \mathrm{~d}$, animals were familiarized with the distractor (dSAT). Distractor sessions were identical to the final stage of training except that a distractor (house light flashing on and off at $0.5 \mathrm{~Hz}$ ) was presented during minutes 9-24 during dialysis sessions and 17-32 during sessions in which NAc infusions were conducted early into the second block of trials (minutes 8-10; total task duration: $40 \mathrm{~min}$ ). Each rat received two dSAT sessions that were separated by at least two SAT sessions or until rats re-established criterion performance in the SAT. Once animals reattained stable SAT performance subsequent to the final dSAT exposure, for at least two consecutive sessions, they underwent cannulation surgery.

\section{Behavioral measures}

For each session, hits, misses, correct rejections, false alarms, and omissions were recorded. The relative number of hits (hits/hits + misses) was calculated for each signal length, and the relative number of correct rejections (correct rejections/correct rejections + false alarms) was also calculated. As an overall measure of attentional performance that integrates both the relative number of hits $(\mathrm{h})$ and the relative number of false alarms (f), an overall performance score (SAT or dSAT score) was calculated as follows: SAT/dSAT $=(\mathrm{h}-\mathrm{f}) /\left[2(\mathrm{~h}+\mathrm{f})-(\mathrm{h}+\mathrm{f})^{2}\right]$. This index was derived from the Sensitivity Index (Frey and Colliver, 1973), except that the SAT/dSAT score was based on the relative number of hits and false alarms, as opposed to the probabilities for hits and false alarms, and thus was not confounded by errors of omission. SAT/dSAT scores range from +1.0 to -1.0 , with +1.0 indicating that all responses were hits and correct rejections, 0 indicating an inability to discriminate between signal and nonsignal events, and -1.0 indicating that all responses were misses and false alarms. SAT/dSAT scores were calculated for each signal duration $\left(\mathrm{SAT}_{500,50,25}\right)$ or averaged over all durations. Errors of omission were recorded separately. Performance measures were calculated for each of the five task blocks.

\section{Surgical procedures}

Implantation of guide cannula for the measurement of $m P F C A C h$ release in $S A T$ and $d S A T$ performing animals. Animals underwent surgery to implant a guide cannula in right mPFC. Surgery was performed under aseptic conditions. Animals were anesthetized initially with $4-5 \%$ isoflurane in an anesthetic chamber (Anesco/SurgiVet). Gas was carried via oxygen at a flow rate of $1 \mathrm{ml} / \mathrm{min}$. Animals' heads were shaved using electric clippers and cleaned with an alcohol wipe. Animals were then mounted to a stereotaxic instrument (David Kopf Instruments). Ophthalmic ointment was used to lubricate animals' eyes. Isoflurane was administered via a facemask and the levels were adjusted to $1.5-2 \%$ for the remainder of surgery. Microdialysis guide cannulas (Model MAB 4.15.IC; Microbiotech) were implanted above the mPFC using the coordinates measured from bregma: AP: $2.9 \mathrm{~mm}$, ML: $0.6 \mathrm{~mm}$, DV: $0.6 \mathrm{~mm}$ below dura. To prevent clogging, the guide cannulas were equipped with stainless steel stylets. A headstage to hold the guide cannula in place was constructed using surgical screws implanted in the skull and dental cement. Animals were given injections of an antibiotic (amikacin, $0.1 \mathrm{ml}$, i.p.) and an analgesic (buprenorphine, $0.01 \mathrm{mg} / \mathrm{kg} / \mathrm{ml}$, i.p.). The area around the headstage was coated with Neosporin.

Implantation of guide cannula for drug infusions into the NAc. Upon reaching stable SAT performance as described above, infusion guide cannula were implanted bilaterally to allow infusions into the shell or the core of the NAc. Furthermore, the cholinergic projections to medial prefrontal or posterior parietal cortex (PPC) were removed in subgroups of animals before the implantation of the guide cannula during the same surgery session. All animals were anesthetized using an anesthesia machine (Anesco/SurgiVet) and with $4-5 \%$ isoflurane. Gas was carried via 


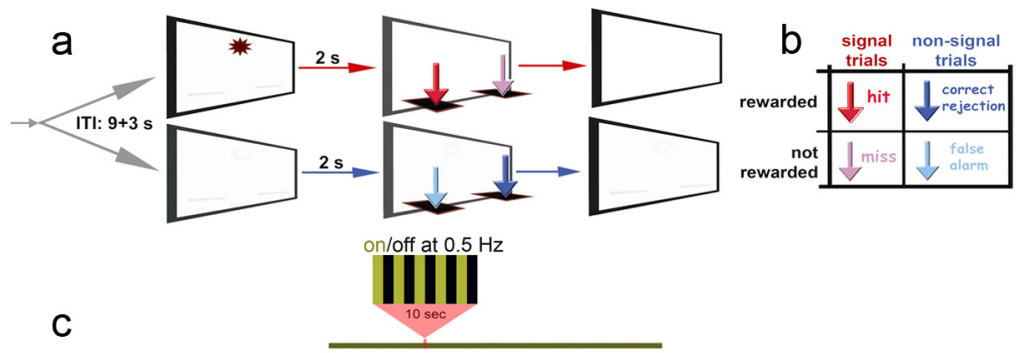

signal event

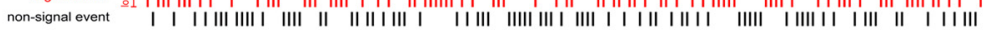
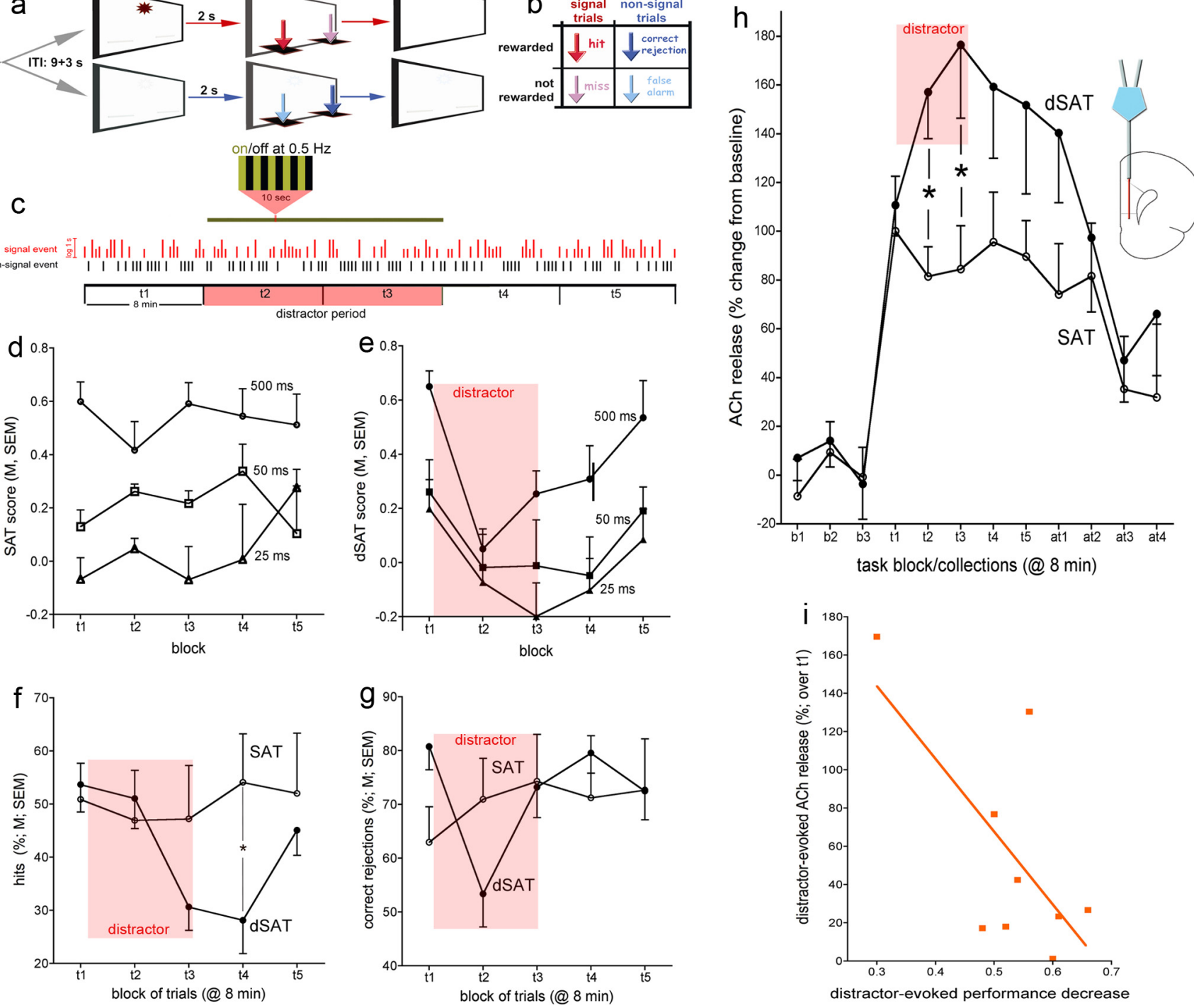

Figure 1. Distractor-induced impairment in attentional performance and prefrontal ACh release in the presence and absence of a distractor. $\boldsymbol{a}$, The SAT consists of randomly ordered signal (light signals 500, 50, or $25 \mathrm{~ms}$ long) and nonsignal events, spaced by $9 \pm 3 \mathrm{~s}$. Two seconds after an event, levers are made available and animals need to respond within $4 \mathrm{~s}$. Following a lever press or after $4 \mathrm{~s}$, levers are withdrawn. $\boldsymbol{b}$, Hits and correct rejections, but not misses and false alarms, are rewarded (note that arrows indicating the four response types in $\boldsymbol{a}$ are color-coded and match arrows in b). Sessions lasted $40 \mathrm{~min}$ and were blocked post hoc into five $8 \mathrm{~min}$ blocks of trials (t1-t5). c, For dSAT testing, the distractor (chamber lights flashing on and off at $0.5 \mathrm{~Hz}$ ) occurred during blocks 2 and 3 in experiments involving monitoring ACh release using microdialysis, and blocks 3 and 4 following intracranial infusions, conducted over the first 2 min of block 2 . The vertical red and black bars illustrate a random sequence of signal and nonsignal trials (signal duration indicated by the length of the red bars). Intracranial infusions into the shell or core of the NAc were conducted remotely to limit interfering with the animals' performance. Therefore, undisturbed block 1 performance data were obtained from all animals before infusions into the NAc core or shell and before the presentation of the distractor during dSAT performance. $\boldsymbol{d}$, In the absence of a distractor (SAT; $n=6)$, performance varied with signal duration and remained stable over the five task blocks (t1-t5).e, Presentation of the distractor during task blocks 2 and 3 transiently impaired performance. The distractor-induced impairment in performance $(d S A T ; n=9)$ was due to decreases in both the relative number of hits $(\boldsymbol{f})$ and correct rejections $(\boldsymbol{g})$. Errors of omission remained low and were not significantly affected by the distractor (Results). During the postdistractor blocks, animals' performance recovered. $\boldsymbol{h}$, SAT performance evoked a steep initial increase in ACh release in the medial PFC. Release levels remained stable throughout the remainder of the performance session. Presentation of the distractor further increased ACh release [b1- $b 3$ depict baseline collections before task onset, $\mathrm{t} 1-\mathrm{t} 5$ depict the five task blocks, and at 1 -at 4 indicate data from four collections following completion of the task ( $8 \mathrm{~min} /$ collection)]. $\boldsymbol{i}$, The severity of the distractor-induced impairment of performance was significantly correlated with distractor-induced increases in cholinergic activity. The abscissa of this graph depicts the differences between $\mathrm{t} 1$ and $\mathrm{t} 2 / \mathrm{t} 3 \mathrm{dSAT}$ scores, with larger numbers indicating more severe impairments. Thus, higher increases in $\mathrm{ACh}$ release were correlated with less severe distractor effects on performance. ${ }^{*} p<0.05$; LSD.

oxygen at a flow rate of $0.6 \mathrm{ml} / \mathrm{min}$. For infusions into the NAc shell $(n=$ 28), a chronic 26 gauge [outer diameter (o.d.) $0.46 \mathrm{~mm}$ ] double-guide cannula with a $2.2 \mathrm{~mm}$ distance between the two $11.0-\mathrm{mm}$-long stainless steel shafts (Plastics One) was implanted at the following stereotaxic coordinates relative to bregma: AP: $+1.0 \mathrm{~mm}, \mathrm{~L}: \pm 1.1 \mathrm{~mm}, \mathrm{DV}:-6.0$ $\mathrm{mm}$ from dura, with the incisor bar set at $-3.3 \mathrm{~mm}$. This placement targeted the infusions to the rostrodorsal region of the NAc shell, the region associated with motivation- and hedonic-generating circuitry and avoiding the more caudal regions of the shell that are involved in aversive reactions (Faure et al., 2010). For infusions into the NAc core $(n=5)$, two chronic 26 gauge (o.d. $0.46 \mathrm{~mm}$ ) single-guide cannulas with a 11.0 mm-long stainless steel shaft (Plastics One) were implanted at the following stereotaxic coordinates relative to bregma: AP: $+1.0 \mathrm{~mm}, \mathrm{~L}: \pm 3.1$ $\mathrm{mm}, \mathrm{DV}:-6.2 \mathrm{~mm}$ at a $10^{\circ}$ angle toward the midline with the tooth bar set at $-3.3 \mathrm{~mm}$. Taste reactivity studies so far have not revealed topographical gradients in the core that would need to be considered to avoid confounds resulting from infusions into subregions associated with different motivational processing. After lowering the guide cannula to the region of interest, the cannula was affixed to the skull with screws and dental cement. Dummy cannulas (o.d. $0.20 \mathrm{~mm}$ ), with no projection past 
the tips of the guide cannula, were inserted to prevent clogging. Animals were given a postoperative injection of amikacin and buprenorphine (doses above) and allowed to recover for at least $3 \mathrm{~d}$ with ad libitum access to food and water.

Cortical cholinergic deafferentation. Cholinergic afferents were removed by infusing the cholino-selective immunotoxin 192 IgG-saporin (192-SAP; Advanced Targeting Systems) into the PFC or PPC (for evidence indicating the selectivity of the deafferentation, see Holley et al., 1994). To deafferent the mPFC $(n=5)$, including pre- and infralimbic region and anterior cingulate cortex, 192-SAP (200 ng/ $\mu \mathrm{l})$ was bolusdelivered at a volume of $0.5 \mu \mathrm{l} /$ site, with two sites per hemisphere at the following stereotaxic coordinates relative to bregma: AP: $+3.7 /+2.6$ $\mathrm{mm}$, L: $\pm 0.7 \mathrm{~mm}, \mathrm{DV}:-3.5 \mathrm{~mm}$ (see also Parikh et al., 2007). For deafferentation of the PPC $(n=5), 192-\mathrm{SAP}(350 \mathrm{ng} / \mu \mathrm{l})$ was bolusinfused at a volume of $0.2 \mu \mathrm{l} /$ site, with four sites per hemisphere at the following stereotaxic coordinates relative to bregma: AP: $-4.0 /-4.7$ $\mathrm{mm}, \mathrm{L}: \pm 2.5 / 3.7 \mathrm{~mm}, \mathrm{DV}:-1.5 \mathrm{~mm}$ or $-1.7 \mathrm{~mm}$, respectively (see also Bucci et al., 1998). Sham surgeries were conducted by infusing mouse IgG-SAP (Advanced Targeting Systems) into the PFC $(n=5)$ or PPC $(n=4)$. For each infusion site, the needle was left in position for $4 \mathrm{~min}$ to allow proper absorption of the toxin in the target region.

\section{Microdialysis methods and determination of ACh concentrations}

Microdialysis sessions began with the removal of the stylet and the insertion of a removable concentric probe with a $3.0 \mathrm{~mm}$ membrane tip (Model MAB 4.15.3; membrane o.d. $0.2 \mathrm{~mm}$, shaft o.d. $0.18 \mathrm{~mm}$; Microbiotech) into the PFC. Animals were perfused at a rate of $0.8 \mu \mathrm{l} / \mathrm{min}$ with artificial CSF, pH $6.8 \pm 0.1$, containing the following (in $\mathrm{mM}$ ): 126.5 $\mathrm{NaCl}, 27.5 \mathrm{NaHCO}_{3}, 2.4 \mathrm{KCl}, 0.5 \mathrm{Na}_{2} \mathrm{SO}_{4}, 0.5 \mathrm{KH}_{2} \mathrm{PO}_{4}, 1.2 \mathrm{CaCl}_{2}, 0.8$ $\mathrm{MgCl}_{2}$, and 5.0 dextrose. Animals were placed into the operant chambers and the probes were perfused for at least $120 \mathrm{~min}$ to allow ACh efflux to stabilize. After this period, collection of baseline samples began, with dialysates collected every $8 \mathrm{~min}$. The last three collections before task onset were averaged to calculate basal ACh efflux. Following baseline collections, the task began. Animals performed either the SAT without distraction $(n=6)$ or the dSAT with distraction $(n=9)$. After the onset of the task, the timing of dialysates collections was adjusted to correct for the dead volume of the probe and outlet tubing, and then five $8 \mathrm{~min}$ dialysate collections were taken. Four additional samples were collected posttask. Animals were then removed from the operant chambers, the microdialysis probes removed and the stylets reinserted, and the rats were returned to their home cages.

Dialysate samples were stored at $-80^{\circ} \mathrm{C}$ until they were analyzed by high-performance liquid chromatography with electrochemical detection (ESA). The mobile phase used contained $35 \mathrm{~mm}$ sodium phosphate, $0.43 \mathrm{~mm}$ ethylenediamine tetracetic acid tetrasodium salt, and $5 \mathrm{ml} / \mathrm{L}$ ProClin (BASi). ACh was separated from choline on a $250 \mathrm{~mm}$ analytical column and catalyzed on a postcolumn solid-phase reactor containing acetyl cholinesterase and choline oxidase. ACh was then hydrolyzed to acetate and choline, and choline was oxidized to hydrogen peroxide and $\beta$ ine. The amount of hydrogen peroxide corresponding to ACh was then detected using a "peroxidase-wired" glassy carbon electrode with an applied potential of $-200 \mathrm{mV}$. To calculate the concentration of ACh in each sample, the integral of the area under the peak was taken and fit to a regression line containing known values of $\mathrm{ACh}$ in the expected range of the in vivo dialysates. The detection limit of this system averaged 2 $\mathrm{fmol} / 15 \mu \mathrm{l}$. Following completion of the experiments, animals were given an overdose of sodium pentobarbital and perfused with phosphate buffer solution and then formalin (Fisher).

\section{Drug infusions into the NAc of SAT or ASAT performing rats}

Rats received bilateral infusions of vehicle (saline; $0.9 \%$ ) or NMDA (Sigma-Aldrich), dissolved in $0.9 \%$ sterile saline. Two $10.0 \mu$ l Hamilton microsyringes each contained $0.5 \mu \mathrm{l}$ of drug or vehicle and were pulled back an additional volume of $0.5 \mu \mathrm{l}$ (airplug) to produce dead volume to prevent uncontrolled diffusion into brain tissue (Kozak et al., 2006). A microinfusion pump (Model CMA/100; Carnegie Medicine) was used to simultaneously and bilaterally infuse $1.0 \mu \mathrm{l}$ per hemisphere over a $2 \mathrm{~min}$ period at a rate of $0.5 \mu \mathrm{l}$ per min.
Infusions began by removing the dummy cannula and internal dummy needles (o.d. $0.20 \mathrm{~mm}$ ). Infusion needles were connected with polyethylene tubing to two Hamilton syringes. After insertion, rats were placed in the operant boxes for $5 \mathrm{~min}$ to acclimate to the operant box before the onset of the task. Remote infusion of vehicle or drug occurred during minutes $8-10$ of the testing session, that is, during the first $2 \mathrm{~min}$ of block 2. Animals were handled and restrained only during insertion, before the onset of the test session, during removal of the internal cannula, and after completion of the test session, but never during a testing session. At the end of the session, the internal cannula was removed, the dummy cannula was reinserted, and animals were returned to their cages for the day. This design allowed demonstration of regular SAT performance during block 1 (before infusions).

The order of infusions was counterbalanced, with at least $2 \mathrm{~d}$ separating two successive infusion sessions or as many sessions as were required for rats to regain stable SAT performance. For the initial experiment on the effects of infusions into the shell of the NAc, animals were randomly assigned to an NMDA dose $(0.01,0.05,0.15 \mu \mathrm{g} / \mu \mathrm{l} / \mathrm{hemisphere;} 0.067$, $0.33,1.01 \mathrm{nmol} /$ hemisphere; $n=10,9$, and 9 , respectively). These doses of NMDA are 60-1000-fold lower than concentrations that elicit neurotoxic effects upon infusion into the NAc (Weissenborn et al., 1996), $10-100$-fold lower than doses that elicit consummatory behavior (Echo et al., 2001), and in the range of doses enhancing long-term memory following infusions into other mesolimbic regions (Rossato et al., 2009). All animals received saline and one dose of NMDA during both a SAT and dSAT session, so that each animal received four infusions total (SATsaline, dSAT-saline; SAT-NMDA, dSAT-NMDA). At an early stage of this study, we observed that only the middle dose of NMDA $(0.33 \mathrm{nmol})$, infused into the NAc shell, improved dSAT performance. Therefore, we limited our tests of the effects of NMDA infusions into the core and the effects of infusions into the shell in animals with cholinergic lesions to this dose.

\section{Histological verification of cannula placements, spread of infusions, and cholinergic deafferentation}

Within a week following the last drug infusion for animals in experiments 1 and 2, half of the animals in each group received infusions of $0.1 \%$ Fluoro-Gold (Fluorochrome) diluted in $0.9 \%$ saline, using the same infusion parameters as described for infusions of saline and NMDA to mark the infusion site. Approximately $40 \mathrm{~min}$ later, animals were deeply anesthetized and transcardially perfused with saline followed by formalin. The remaining animals were anesthetized and transcardially perfused with saline followed by formalin for cannula placement only. Brains were postfixed in formalin overnight at $4^{\circ} \mathrm{C}$ and transferred to a $30 \%$ sucrose 0.1 m PBS. Coronal sections $(40 \mu \mathrm{m})$ surrounding the cannula site were sliced using a freezing microtome (CM 2000R; Leica) and mounted.

Fluorogold sections were coverslipped and examined using a Leica DM 6000B microscope (Leica Microsystems) equipped with an A4 filter cube (360/40 excitation bandpass filter) at $10 \times$ with an exposure time of 2 s. Photographs were captured using MCID Core 7.0 imaging software (Interfocus Imaging) and were tiled in a $2 \times 2$ fashion using flat field correction to assess the extent of fluorogold diffusion. Fluorogold emits blue under these conditions, whereas nonfluorescent objects, such as the background, remain dark. Images were then transferred to Adobe Photoshop CS3 software in hue, saturation, and brightness color mode where pixels with a brightness value darker than $50 \%$ (range $0-100 \%$ ) were made transparent. The residual images were mapped onto their corresponding atlas locations and were used to indicate the extent of infusions into the shell or core.

Loss of cortical cholinergic afferents was determined on the basis of ChAT-immunostained sections. Animals were deeply anesthetized and transcardially perfused within a week following the last drug infusion with saline followed by $4 \%$ paraformaldehyde in $0.1 \mathrm{M} \mathrm{PBS}$, pH 7.4. Brains were removed and postfixed overnight at $4^{\circ} \mathrm{C}$ and stored in $30 \%$ sucrose in $0.1 \mathrm{M}$ PBS for $72 \mathrm{~h}$. Coronal sections $(40 \mu \mathrm{m})$ of the brains were sliced using a freezing microtome (CM 2000R; Leica) and stored in $0.1 \mathrm{M}$ PBS until additional processing. ChAT immunostaining was accomplished by using a Vectastain Elite ABC kit (PK-6105; Vector Laborato- 
ries) and a primary antibody (polyclonal goat anti-ChAT; Millipore). An orbital shaker was used throughout incubation and rinse periods. Sections were first rinsed in $0.1 \mathrm{~m}$ phosphate buffer ( $\mathrm{pH}$ 7.4) three times for $5 \mathrm{~min}$ each and were then incubated in $0.3 \%$ peroxide for $30 \mathrm{~min}$. They were rinsed again in $0.1 \mathrm{~m}$ phosphate buffer two times for $5 \mathrm{~min}$ each. After rinsing, sections were then incubated for $1 \mathrm{~h}$ in a $1.5 \%$ normal blocking serum with $0.2 \%$ Triton-X. After blocking, tissue was immediately transferred to incubate in the primary antibody (goat anti-ChAT made in rabbit, 1:250) overnight at $4^{\circ} \mathrm{C}$. The next day, sections were rinsed three times in $0.1 \mathrm{M}$ PBS with $0.2 \%$ Triton-X. They were then incubated in the biotinylated secondary antibody (biotinylated rabbit anti-goat, 1:200; supplied in the Vectastain Elite ABC kit) for $2 \mathrm{~h}$. After being rinsed three times for $5 \mathrm{~min}$ each in $0.2 \%$ Triton-X in $0.1 \mathrm{M}$ phosphate buffer, tissue was incubated with the avidin-biotin complex (1:25) for $30 \mathrm{~min}$. Sections were rinsed three times for $5 \mathrm{~min}$ each in $0.1 \mathrm{M}$ phosphate buffer. Tissue was then rinsed in a peroxidase substrate solution of $0.4 \%$ diaminobenzidine (DAB) and $0.19 \%$ nickel (II) chloride in $0.1 \mathrm{M}$ phosphate buffer; $10 \mu \mathrm{l}$ of $30 \%$ hydrogen peroxide was added immediately before use. Once sections reached a desired color $(\sim 5 \mathrm{~min})$, they were rinsed with $0.1 \mathrm{M}$ phosphate buffer three times for $5 \mathrm{~min}$ each. Omission of the primary antibody resulted in no specific staining, supporting the specificity of this protocol. Sections were mounted on gelatin-coated slides and were allowed to dry overnight. The following day, slides were dehydrated in an ascending alcohol series and defatted in xylene before coverslipping.

ChAT-positive fiber density throughout the frontoparietal cortex was quantified using a grid-counting technique described earlier (Stichel and Singer, 1987; Ross et al., 2005; Parikh and Sarter, 2006). Briefly, ChATIR-positive fibers were visualized in layers III/IV using a Leica DM 4000B digital microscope and a SpotFlex digital camera (Model 15.2). Images were captured at $20 \times$ along four rostrocaudal planes. The two most rostral planes were used to quantify ChAT-positive fibers in the prelimbic and infralimbic regions and as a control primary motor cortex. The two more caudal sections were used to quantify fibers throughout the parietal association cortex and, as a control region, the retrosplenial agranular cortex. Using Adobe Photoshop CS3 software, $50 \mu \mathrm{m}$ squares were superimposed over the areas to be counted $(200 \times 200 \mu \mathrm{m})$ (see Fig. 4 for location of counting areas). ChAT-positive stained fibers that traversed any line of this grid were counted. This method does not generate absolute and bias-free counts but a semiquantitative estimate of the immunotoxin-induced decrease of the density of cortical cholinergic innervation.

\section{Statistical methods}

Because of the complexity of the designs used for the multiple experiments described below, the main factors and statistical methods are identified briefly in the description of results. Generally, mixed-design ANOVAs were used to determine the performance effects of infusion dose, site (shell vs core), task type (dSAT vs SAT), task block (t1-t5), and signal duration (where applicable). Effects of infusions of the immunotoxin on ChAT-positive fiber counts likewise were analyzed using a mixed-design ANOVA on the effects of group (sham, PFC deafferented, or PPC deafferented), cortical region, and hemisphere. Post hoc multiple comparisons were conducted using $t$ test and Fisher's least significant difference (LSD) test. Statistical analyses were performed using SPSS for Windows (V. 17.0; SPSS). In cases of violation of the sphericity assumption, Huyhn-Feldt-corrected $F$ values are given. Exact $p$ values are reported for significant results, as recommended by Greenwald et al. (1996).

\section{Results \\ Augmented increases in prefrontal ACh release mediate attentional performance in the presence of a distractor}

The goal of the first experiment was to characterize attentional performance-associated increases in prefrontal ACh release in the absence and presence of a distractor. The effects of the distractor on performance are described first, followed by effects on performance-associated ACh release (see Fig. $1 a-c$ for an illustration of the task and the implementation of a distractor challenge).

\section{Distractor-induced impairments in performance}

In the absence of a distractor (SAT), attentional performance remained stable throughout the task period (Fig. 1d). In contrast, presentation of the distractor during blocks 2 and 3 robustly impaired performance, followed by recovery of performance during the postdistractor period (main effect of task block on SAT/dSAT scores: $F_{(4,52)}=3.37, p=0.02$; block $\times$ task type: $F_{(4,52)}=3.09, p=0.03$ ) (Fig. 1e). Performance varied with signal duration (main effect of duration: $F_{(2,26)}=24.48, p=$ 0.001 ), and the distractor did not modify this effect (all interactions involving signal duration: $F<1.34$ ).

The distractor impaired response accuracy for both signal (block $\times$ task type: $F_{(4,52)}=3.97, p=0.01$ ) (Fig. $1 f$ ) and nonsignal trials (block $\times$ task type: $F_{(4,52)}=4.18, p=0.01$ ) (Fig. $1 g$ ). Post hoc analyses on the effects of hits indicated that dSAT, but not SAT, performance varied by task block (dSAT: $F_{(4,32)}=7.82$, $p=0.001$; SAT: $\left.F_{(4,20)}=0.43, p=0.78\right)$ and that the relative number of hits was lower in the second block of the distractor period ( $\mathrm{t} 3$ ) and the subsequent block of trials ( $\mathrm{t} 4)$, when compared with the predistractor block ( $p$ values $<0.01$ ). Likewise, block affected the correct rejection rate during dSAT performance $\left(F_{(4,32)}=7.39, p=0.001\right)$. Correct rejections during the first distractor block were lower than during any other block of trials ( $p$ values $<0.04$ ).

Importantly, the distractor did not affect the number of errors of omission (main effects of block, task type, and interaction; $F$ values $<0.69$ ). Animals omitted $<10 \%$ of all trials, including during the second (1.90\%) and third (4.13\%) blocks of trials when the distractor was presented and response accuracy was impaired.

\section{Performance-associated ACh release}

SAT and dSAT performance-associated ACh release, measured in the prelimbic and ventral anterior cingulate cortex, is illustrated in Figure $1 h$ (see inset for an illustration of probe placement). Pretask basal ACh release did not differ between SAT and dSAT performing animals $\left(t_{(13)}=1.14, p=0.28,4.89 \mathrm{fmol} / 15 \mu \mathrm{l}\right)$, justifying the calculation of performance-associated increases in ACh as percentage changes from baseline (see Materials and Methods for determination of basal release).

The increases in ACh release differed between SAT and dSAT performing animals (task type: $F_{(1,13)}=4.91, p=0.04$; SAT: $90.26 \pm 21.25 \%$; dSAT: $151.03 \pm 17.35 \%)$. As would be expected, performance-associated increases in ACh release were statistically similar in both groups for the first task block or collection interval (t1), before the onset of the distractor presentation in dSAT performing animals $\left(t_{(13)}=0.45, p=0.66\right)$. Post hoc comparisons indicated that ACh release was significantly higher during both distractor blocks $\left(\mathrm{t} 2: t_{(13)}=3.00, p=0.01\right.$; t3: $\left.t_{(13)}=2.30, p=0.04\right)$. Following termination of the distractor, ACh release levels no longer differed by task type ( $\mathrm{t} 4$, t5; $\left.F_{(1,13)}=2.33, p=0.15\right)$.

The distractor-induced increases in ACh release correlated with the distractor-induced impairment in performance (Fig. 1i). For this analysis, individual ACh release levels and dSAT scores from the two distractor blocks were averaged and subtracted from the values obtained from the predistractor block of trials. The correlation between distractor-induced increases in ACh release and decreases in performance was significantly different from zero $(r=-0.68, p=0.04)$. For every $38 \%$ increase in ACh 


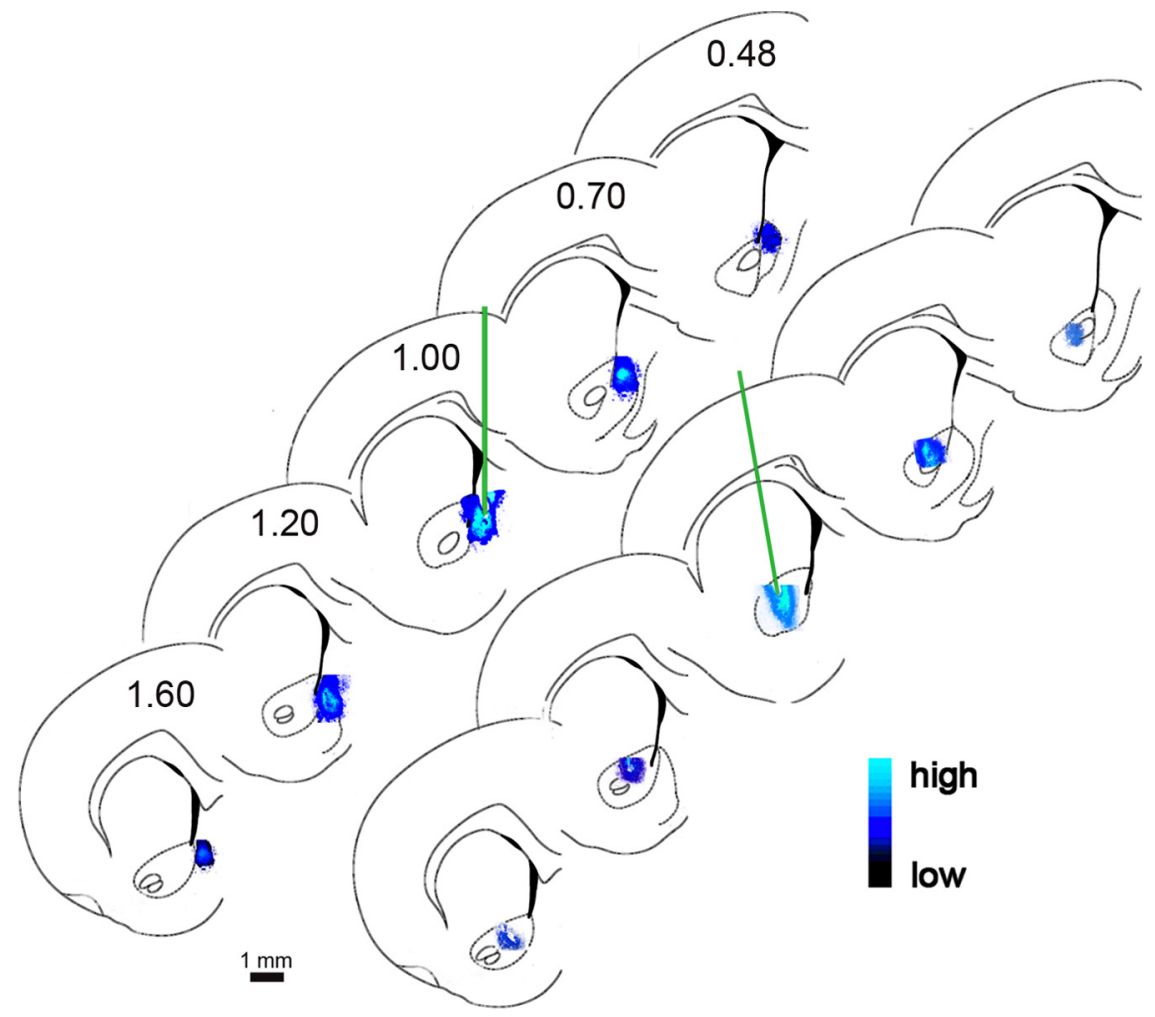

Figure 2. Reconstruction of the infusion sites in the shell (top) and core (bottom) of the NAc and estimation of the infusion spread based on infusions of Fluoro-Gold (see Materials and Methods for details). Similar to our earlier studies that involved infusion of compounds into the shell of the NAc (Himmelheber et al., 2000), the fluorophore occupied an asymmetrical space, likely confined in part by structural boundaries (see also Allen et al., 2008). Infusions into the shell were intended to occupy the more rostral half of this subregion (see Materials and Methods; Faure et al., 2010).

release, the distractor effect decreased by one unit $(0.1)$ of the dSAT score.

\section{Stimulation of NMDA receptors in the shell, but not core, of the NAc enhances dSAT, but not SAT, performance}

The results from the first experiment are consistent with the hypothesis that higher levels of distractor-evoked mPFC cholinergic activity are associated with less severe distractor-induced impairments in attentional performance. The second experiment used an experimental manipulation, stimulation of NMDA receptors in the shell of the NAc, that was previously demonstrated to activate mPFC cholinergic neurotransmission (Brooks et al., 2007; Zmarowski et al., 2007; Alexander et al., 2009). We hypothesized that NAc NMDA receptor stimulation would augment distractor-evoked increases in ACh release, thereby further reducing the impact of the distractor. Ideally, this hypothesis would be tested by measuring ACh release in dSAT performing animals while simultaneously infusing NMDA bilaterally into the NAc. However, such an experiment was technically infeasible because of the challenges associated with forebrain triple cannulation and inadequate task performance resulting from inserting and connecting bilateral infusion needles as well as inserting a dialysis probe and connecting inlets and outlets. Instead, the third experiment addressed the necessity of prefrontal cholinergic input for demonstrating effects of NAc NMDA infusions (see below).

Location and spread of infusions into the shell or core of the NAc The location and spread of infusions into the shell and core of the NAc were estimated on the basis of infusions of Fluoro-Gold at the end of all experiments (see also Himmelheber et al., 2000).
Figure 2 depicts the location and estimate of infusion spread based on microscopic measurements of luminosity. Infusions into the shell remained largely confined to the more anterior and more dorsal portions of this region, spreading $\sim 1.0 \mathrm{~mm}$ along the anterior-posterior axis. Infusions into the core did not spread into the adjacent shell or caudate-putamen.

Effects of NAc shell and core infusions on SAT and dSAT performance (omnibus test)

The analysis of the effects of group (shell vs core), task type (SAT vs dSAT), block of trials ( $\mathrm{t} 1-\mathrm{t} 5)$, signal duration $(500,50,25$ $\mathrm{ms})$, and dose of NMDA (0, 0.067, 0.33, $1.01 \mathrm{nmol} /$ hemisphere) indicated a significant interaction between all factors $\left(F_{(8,464)}=2.72, p=0.01\right)$.

Performance before shell or core infusions and before distractor presentation ( $t 1)$ Animals received a total of four infusions, twice of vehicle and twice of one dose of NMDA, infused early into the second block of trials during a SAT and a dSAT session (order was counterbalanced). Thus, each animal served as its own control and dose was a between-subjects factor. Before the infusion of drug into the core or shell of the NAc and the presentation of the distractor to dSAT performing animals, all groups performed comparably [main effect of task on SAT scores: $F_{(1,58)}=1.10, p=0.30$; main effect of NAc site: $F_{(1,58)}=2.74, p=$ 0.10 ; main effect of dose (to be infused): $\left.F_{(3,58)}=1.43, p=0.24\right]$. Animals generally omitted few trials; however, animals prepared for infusions into the core omitted significantly more trials than animals prepared for infusions into the shell $\left(F_{(1,58)}=27.08, p<\right.$ 0.001; shell: $3.79 \pm 0.81 \%$ omissions; core: $15.19 \pm 2.06 \%$ ) (Fig. 3 , left column). Thus, and with the exception of higher omissions in core-implanted animals, the effects of infusions of NMDA on SAT and dSAT performance were assessed on the basis of statistically similar levels of performance before infusions and before distractor presentation.

Acute performance effects of remote intracranial infusions ( $t 2$ ) Intracranial infusions were conducted over the first $2 \mathrm{~min}$ of the second block of trials. NAc infusions were performed remotely to minimize interfering with the animals' performance. Still, infusions into the shell and core acutely increased the number of omissions (main effect of dose: $F_{(3,58)}=17.84, p<0.001$ ); post hoc comparisons indicated that the two higher doses of NMDA significantly increased the relative number of omissions [vehicle: $10.24 \pm 3.85 \%$; 0.067 nmol: $5.25 \pm 4.56 \%$; 0.33 nmol: $36.43 \pm$ $4.33 \%$ (LSD, $p<0.001)$; 1.01 nmol: $37.38 \pm 4.80 \%(p<0.001)$ ]. Furthermore, and consistent with the observation that coreimplanted animals omitted more trials even before infusions (above), omissions during and after infusions into the core were higher than in shell-infused animals $\left(F_{(1,58)}=19.94, p<0.001\right.$; shell: $15.86 \pm 2.15 \%$ omissions; core: $36.27 \pm 5.28 \%)$. Infusions of NMDA into the core further increased the errors of omission, whereas infusions into the shell did not (note that infusions into 
the core were limited to the dose found to restore dSAT performance following NAc shell infusions, $0.33 \mathrm{nmol}$; NAc site $X$ dose: $F_{(1,58)}=10.56, p=0.002$; NMDA/ shell: $14.08 \pm 4.80 \%$; NMDA/core: $58.77 \pm 7.46 \%)$. Because of the relatively high number of errors of omission observed during the infusion block of trials, and because of the focus of this study on the mechanisms mediating attentional performance under distractor challenges, the main analyses of these experiments focused on the subsequent distractor blocks and their SAT counterparts. This increase in omissions did not generalize to subsequent blocks and was not associated with shell infusions that restored dSAT performance.

Infusions of NMDA into the NAc shell on performance during the distractor $(t 3, t 4)$ Infusions of NMDA improved dSAT performance $\left(F_{(3,52)}=2.90, p=0.04\right)$. As illustrated in Figure $3 c$, the distractor impaired performance, with the averaged dSAT score for vehicle-treated animals approaching zero, indicating random lever selection. While the distractor was flashing, the middle dose of NMDA restored performance to levels that were statistically similar to those observed in these animals following infusions of vehicle and in the absence of the distractor ( post hoc comparison against the effects of vehicle on equivalent SAT blocks $\mathrm{t} 3$ and $\mathrm{t} 4 ; F_{(1,16)}=$ 2.61, $p=0.13$; vehicle/SAT: $0.36 \pm 0.06$; NMDA/dSAT: $0.22 \pm 0.06)$. Performance during distractor blocks $\mathrm{t} 3$ and $\mathrm{t} 4 \mathrm{re-}$ mained dependent on signal duration $\left(F_{(2,104)}=2.10, p<0.001\right)$, and the effects of NMDA did not interact with duration and did not differ between distractor blocks $\mathrm{t} 3$ and $\mathrm{t} 4$ (main effect of block and all interactions: $F<1.19$ ).

The beneficial effect of NMDA on the animals' overall performance in the presence of a distractor resulted from increases in hits as well as correct rejections. However, the effects of NMDA on hits remained insignificant $\left(F_{(3,52)}=1.46, p=\right.$ 0.24; all other interactions involving dose: $F<1.42)$. The significant effect of dose on correct rejections $\left(F_{(3,52)}=3.07, p=\right.$ $0.04)$ mainly reflected an impairment produced by the highest dose of NMDA (Fig. 3i). The disruptive effect of the highest dose of NMDA was also indicated by an increase in omissions $\left(F_{(3,52)}=5.51\right.$, $p=0.02$ ) (Fig. 3l).

Following the termination of the distractor, block $\mathrm{t} 5$ performance recovered for all groups of animals (data not shown). Although postdistractor dSAT scores of animals infused with the middle dose of
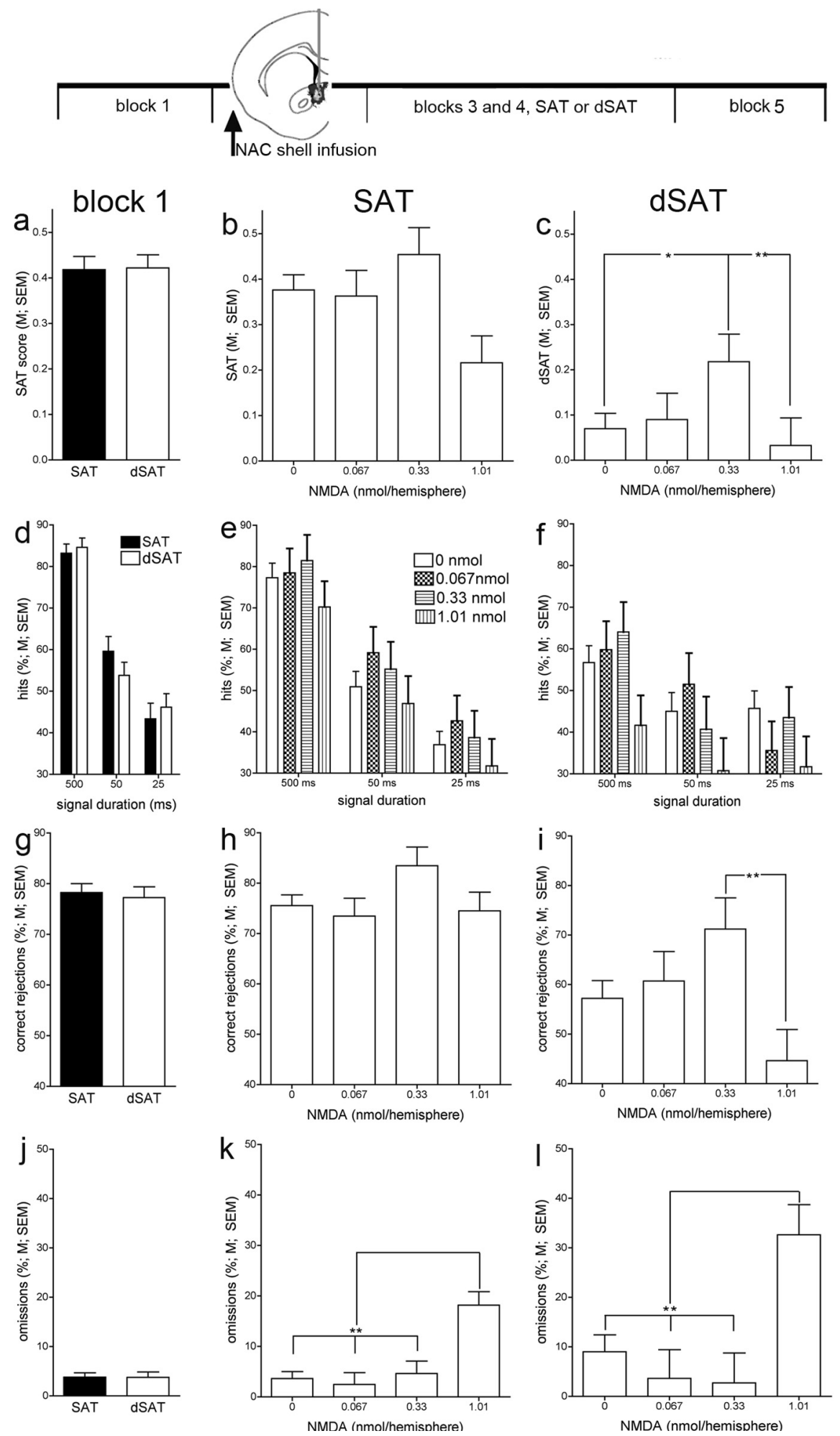

Figure 3. Effects of infusions of NMDA into the NAc shell $(n=28)$ on attentional performance in the absence $(S A T ; \boldsymbol{b}, \boldsymbol{e}, \boldsymbol{h}, \boldsymbol{k})$ or presence (dSAT; $\boldsymbol{c}, \boldsymbol{f}, \boldsymbol{i}, \boldsymbol{I})$ of a distractor (task blocks 3 and 4). The graphs in the left column $(\boldsymbol{a}, \boldsymbol{d}, \boldsymbol{g}, \boldsymbol{j})$ depict the animals' performance during the first block of trials, before infusions into the NAc shell of performing animals and for both task conditions. In SAT performing animals (middle column), NAc infusions did not affect performance except for an increase in omissions caused by the highest dose of NMDA ( $\boldsymbol{k}$ ). In contrast, in dSAT performing animals, infusions of NMDA restored the animals' performance (dSAT score) to a level statistically similar to the performance of vehicle-treated animals in the absence of a distractor. This effect was due to the combined effects on hits $(\boldsymbol{f})$ and correct rejections $(\boldsymbol{i})$, although neither individual measure was solely responsible for the overall effect of NMDA. $\boldsymbol{k}, \boldsymbol{I}$, In SAT and dSAT performing animals, the highest dose of NMDA increased omissions $\left({ }^{*} p<0.05 ;{ }^{* *} p<0.01\right.$; LSD). 
sham
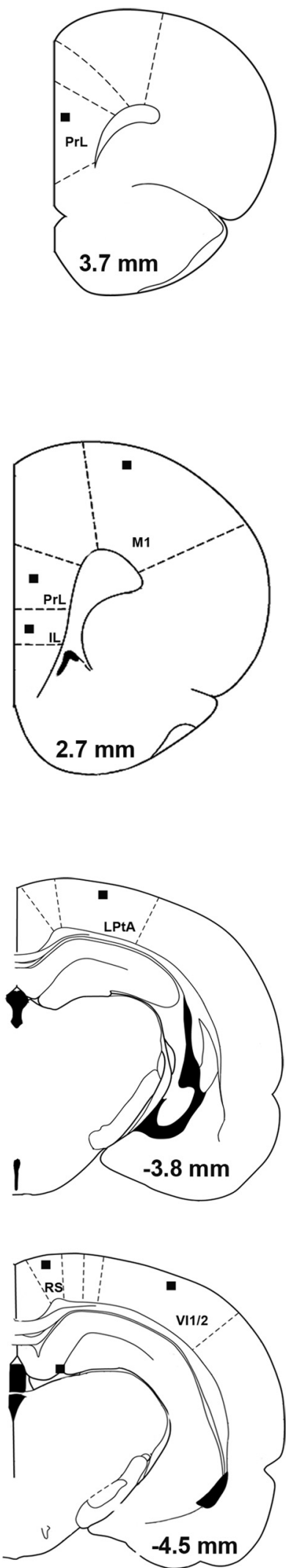
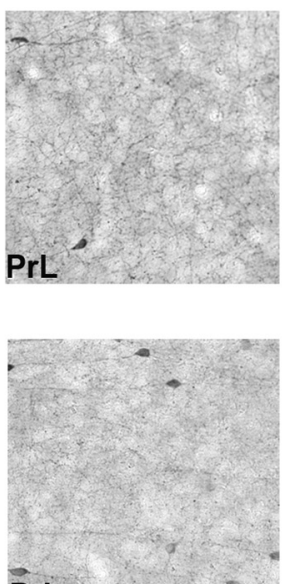

PrL
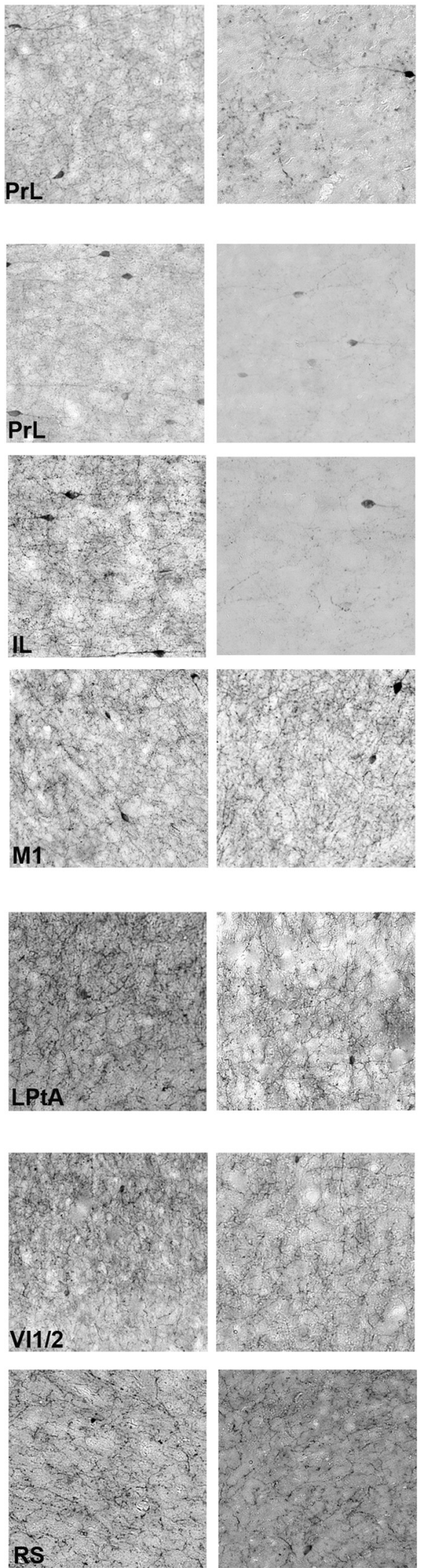

PFC-deaff
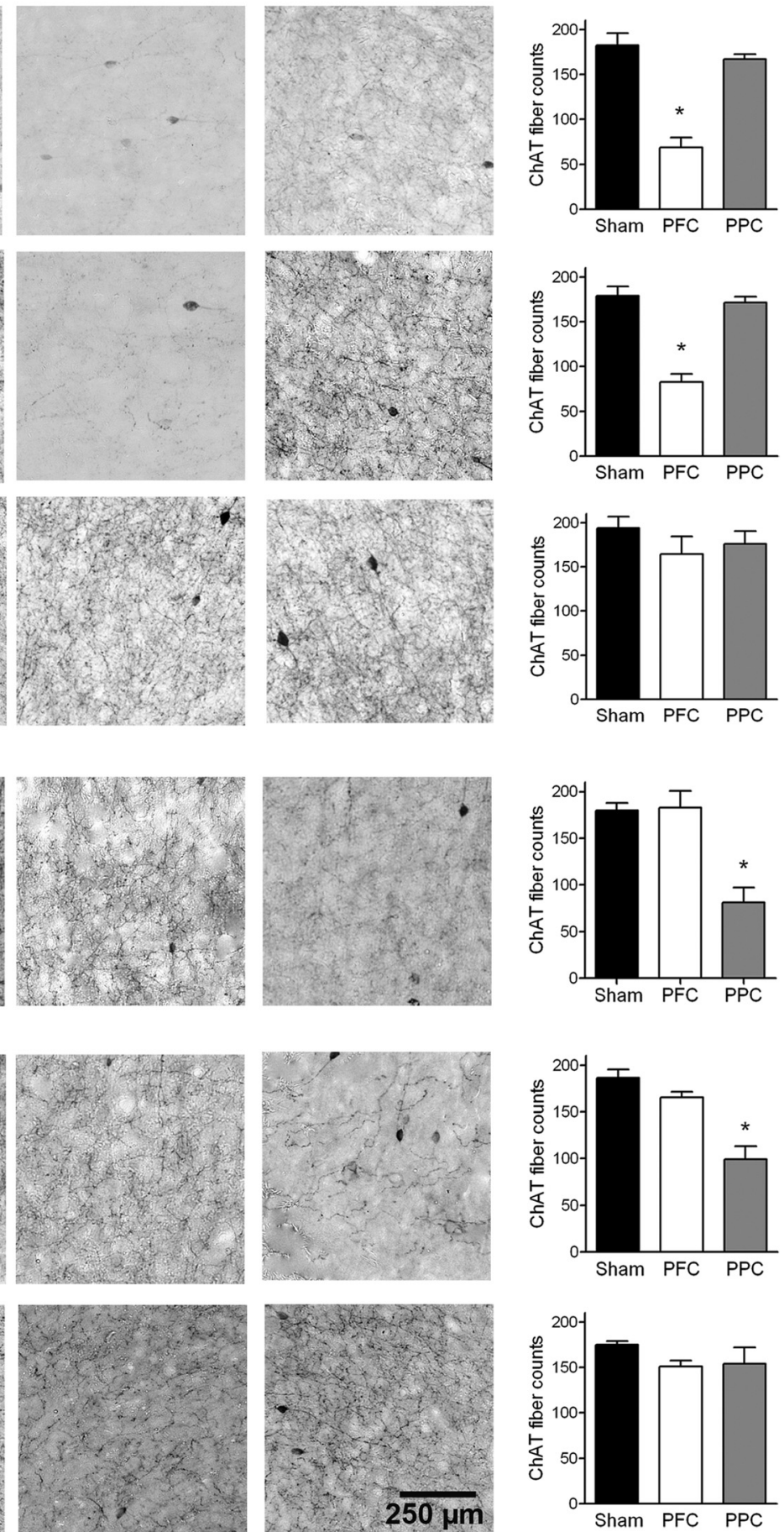

Figure 4. Removal of cholinergic input to the mPFC or PPC by infusions of the immunotoxin $192 \mathrm{lgG}$-saporin into these cortical regions. The schematic coronal sections on the left indicate the areas in which ChAT-positive fibers were counted (see black squares representing the location of the $200 \times 200 \mu \mathrm{m}$ counting areas; not drawn to scale; anterior-posterior levels based on bregma). (Figure legend continues.) 
NMDA continued to be the highest among the four groups, the effect was no longer significant (vehicle: $0.023 \pm 0.049 ; 0.33 \mathrm{nmol}$ : $\left.0.37 \pm 0.081 ; F_{(3,52)}=1.04, p=0.38\right)$.

Infusions into the NAc shell on SAT performance

Infusions of NMDA into the NAc shell did not affect the animals' SAT performance, except for an increase in omissions caused by the highest doses of NMDA (SAT scores, hits, correct rejections: $F$ values $<1.56$; omissions: $F_{(3,52)}=10.28, p<0.001$ ) (Fig. 3, middle column).

\section{Infusions of NMDA into the NAc core on ASAT and SAT performance}

As was the case in the experiment on the effects of infusions of NMDA into the shell of the NAc, the distractor impaired the performance of vehicle-treated animals to the level of random lever selection. However, infusions into the core did not alter dSAT performance (main effect of dose and all interactions involving dose on dSAT scores: $F$ values $<1.62$ ). Core infusions increased the errors of omissions during the distractor period $\left(F_{(1,4)}=12.45, p=0.02\right)$. Performance during the postdistractor block $\mathrm{t} 5$ likewise did not benefit from core infusions $[F$ values $<$ 7.28; this relatively high $F$ value reflected a trend ( $p=0.054$ ) for a decrease in hits following NMDA infusions; vehicle: $34.45 \pm$ $3.04 \%$ hits (averaged over all durations); 0.33 nmol NMDA: $20.75 \pm 5.18 \%$ ].

SAT performance remained unaffected by core infusions $(F$ values $<4.01)$. Moreover, nonsignificant trends for effects, specifically on omissions, all were in the direction of performance impairments. Thus, infusions into the core of the NAc benefited neither SAT nor dSAT performance but rather resulted in trends toward impairment of performance.

\section{Removal of cholinergic input to PFC or PPC abolishes the enhancing effects of NAc shell stimulation}

This experiment assessed the necessity of cholinergic inputs to the cortex for enhancing dSAT performance by NAc stimulation. Figure 4 illustrates the loss of cholinergic inputs to medial prefrontal or posterior parietal cortex, produced by intracortical infusions of 192-SAP. Infusions of the immunotoxin decreased the cholinergic innervation of the $\mathrm{mPFC}$ along $2.00 \mathrm{~mm}$ of its anterior-posterior extension ( +2.00 to $+4.00 \mathrm{~mm}$ based on bregma). PPC cholinergic deafferentation included parietal regions extending from bregma $-3.70 \mathrm{~mm}$ to $-5.00 \mathrm{~mm}$. Infusions of the immunotoxin significantly reduced ChAT-positive fiber density in $\mathrm{mPFC}$ (by an average of $56.17 \%$ ) and PPC (50.81\% decrease) of both hemispheres (Fig. 4).

As illustrated in Figure 5, infusions of NMDA into the shell of the NAc attenuated the detrimental effects of the distractor in

\footnotetext{
$\leftarrow$

(Figure legend continued.) The microphotographs exemplify ChAT-positive fibers and cells in the counting regions for sham-operated, PFC-deafferented, and PPC-deafferented animals (scale for all photomicrographs is indicated in the lower right microphotograph). The microphotographs showing deafferented mPFC or PPC indicate the presence of residual ChAT-positive, large bipolar cortical interneurons. These neurons do not express $\mathrm{p} 75$ receptors and thus are not lesioned by the immunotoxin (Heckers et al., 1994). The function of these neurons is poorly understood (von Engelhardt et al., 2007). The bar graphs on the right indicate ChAT-positive fiber counts and the result of multiple comparisons (LSD) based on significant effects of group and interactions between group and region as indicated by ANOVA ( $F$ values $>3.16, p<$ 0.001 ). Collectively, these analyses confirmed the efficacy and regional selectivity (mPFC vs PPC) of the removal of cholinergic input. IL, Infralimbic cortex; LPtA, lateral parietal association cortex; M1, primary motor cortex; PrL, prelimbic cortex; RS, retrosplenial (agranular) cortex; VI1/2, primary/secondary visual cortex.
}

sham-operated animals, reproducing the result described above. Removal of cholinergic input to PFC or PPC abolished this effect (Fig. 5). An omnibus ANOVA was conducted over all three groups of animals (PFC and PPC sham operated, PFC deafferented, PPC deafferented), blocks of trials ( $t 1-t 5)$, and dose of NMDA. This analysis indicated a significant interaction between the effects of all three factors $\left(F_{(8,64)}=2.53, p=0.02\right.$; main effect of group: $F=1.23$, n.s.). To locate the source of the three-way interaction, two-way ANOVAs on the effects of block and dose were conducted for the data from each group. These analyses indicated a significant interaction only for sham-operated animals (block $\times$ dose: $F_{(4,32)}=8.26, p<0.001$ ) but not for PFC- or PPC-deafferented animals $(F$ values $<0.81)$. This result indicated that cholinergic deafferentation abolished the effects of NMDA.

Before infusions ( $\mathrm{t} 1$ ), the performance of sham-operated animals to be infused with either vehicle or NMDA did not differ (all measures; $F$ values $<1.53$ ). As was observed before, infusions acutely (block t2) impaired performance and increased the omissions; therefore, the data from this block were not further analyzed. Importantly, the performance during the distractor blocks $(\mathrm{t} 3, \mathrm{t} 4)$ again was significantly enhanced by infusions of NMDA in the NAc shell. Sham-operated animals' dSAT scores benefited from NMDA infusions $(0.33 \mathrm{nmol})$ into the shell $\left(F_{(1,8)}=14.56\right.$, $p=0.005$ ) (Fig. 5a). Furthermore, this effect was due to both increases in hits and correct rejections, with the increase on hits reaching significance $\left(F_{(1,8)}=8.87, p=0.02\right.$; correct rejections: $\left.F_{(1,8)}=1.86, p=0.21\right)$. Finally, postdistractor block performance was unaffected by NMDA $(F$ values $<1.73)$.

\section{Discussion}

Sustaining and recovering attentional performance in the face of distractor challenges require enhanced modulation of frontoparietal attention networks. Our findings indicate that NAc-cholinergic interactions mediate, and are necessary for, attentional performance under challenging conditions, and that stimulation of this circuit attenuates the impact of a distractor. Moreover, our results specify the role of cholinergic neurotransmission during performance challenges and support a new framework for conceptualizing and treating attentional symptoms and disorders.

The main results from these experiments indicate that stimulation of the shell of the NAc, via activation of cholinergic projections to the cortex, enhances attentional performance in the presence of a distractor. The improvement of dSAT performance reached a level that was statistically similar to that seen in the absence of the distractor. NAc shell infusions did not benefit performance in the absence of the distractor (SAT). NMDA infusions into the core of the NAc improved neither dSAT nor SAT performance but increased errors of omission. Cholinergic projections to PFC and PPC are necessary for the demonstration of the beneficial effects of NMDA receptor stimulation in the shell of the NAc.

The lack of effect of NAc stimulation on performance in the absence of a distractor suggests that such stimulation does not merely enhance, bottom-up, the motivation to perform (Bowman and Brown, 1998; Salamone and Correa, 2002). Accordingly, such stimulation is not predicted to reinstate attentional performance of unmotivated subjects. Indeed, stimulation of AMPA receptors in the shell inhibits deprivation-induced feeding and sucrose intake (Stratford et al., 1998), further rejecting nonspecific motivational contributions to our main finding. Rather, stimulation of NAc ionotropic glutamate receptors amplifies the activation of attention systems specifically in interac- 


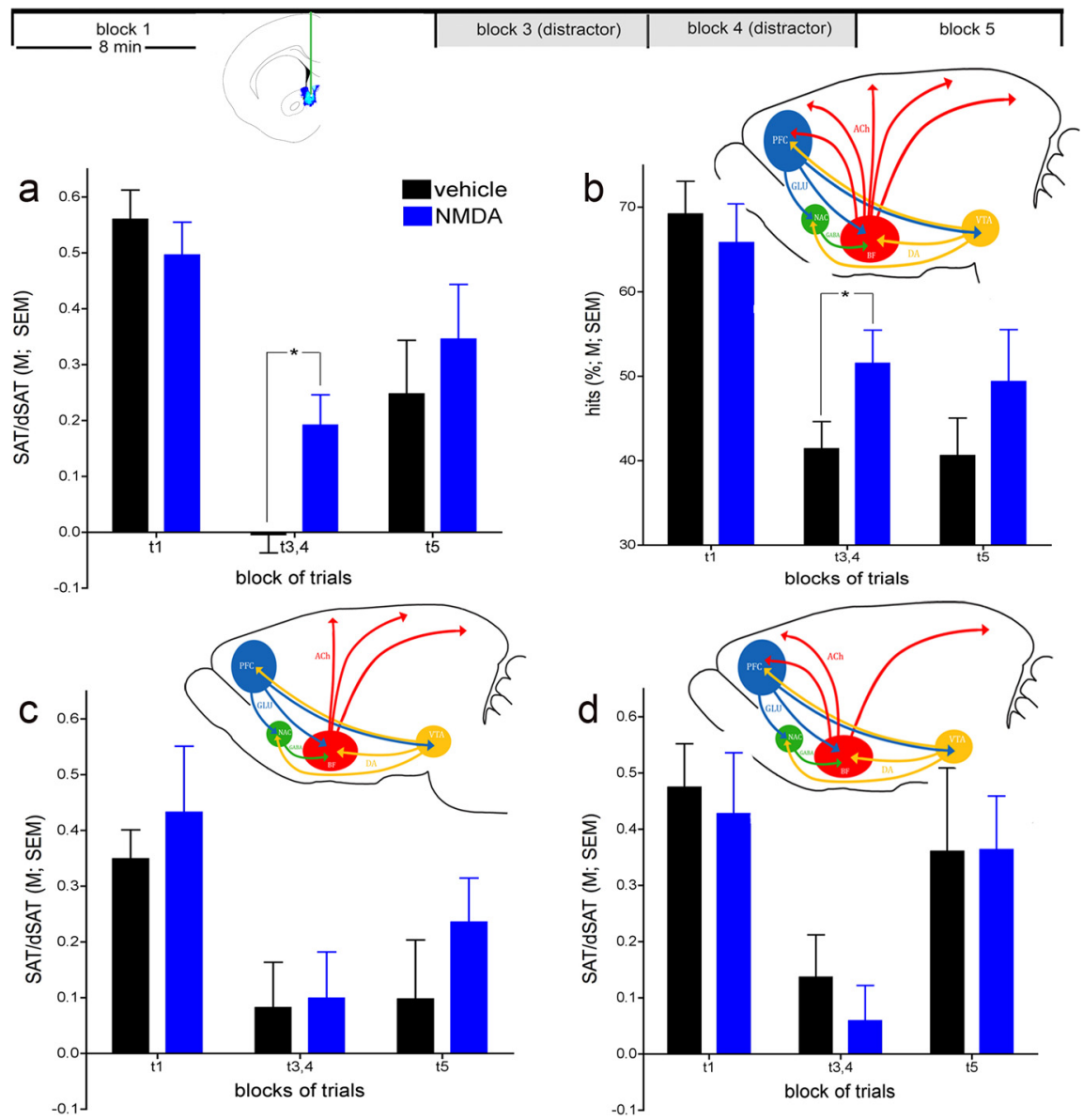

Figure 5. Infusions of NMDA into the shell of the NAc restored the performance during the distractor blocks $(\mathrm{t} 3, \mathrm{t} 4)$ in animals that received sham surgeries for cholinergic deafferentation of the prefrontal and posterior parietal cortex $(\boldsymbol{a}, \boldsymbol{b})$, but not following removal of prefrontal (c) or posterior parietal $(\boldsymbol{d})$ cholinergic inputs $(n=19)$. $\boldsymbol{a}$, Infusions of NMDA $(0.33 \mathrm{nmol} /$ hemisphere) restored the animals' dSAT performance ( $\mathrm{t} 3, \mathrm{t} 4)$, reproducing the effect observed in nonoperated animals. However, in this case, the effects on hits $(\boldsymbol{b})$, but not correct rejections (data not shown), also reached significance. The inset in $\boldsymbol{b}$ illustrates the intact cortical cholinergic input system arising from the basal forebrain (BF), BF afferent systems originating from PFC, NAc, and ventral tegmentum (VTA), as well as the projections of the VTA to PFC and NAc, color coded to reflect type of projection: blue, glutamate (GLU); green, GABA; red, acetyleholine (ACh); yellow, dopamine (DA). The corresponding insets in c and $\boldsymbol{d}$ illustrate the removal of PFC and PPC cholinergic projections, respectively. In deafferented animals, NMDA infusions failed to benefit dSAT performance $\left({ }^{*} p<0.05 ;\right.$ LSD $)$.

tion with control mechanisms that are recruited in response to distractor presentation, performance decline, and reward loss.

The selectivity of the effects of stimulation of the NAc shell was predicted primarily based on prior effects on basal cortical ACh release (references above). However, the results from recent experiments confirmed a selective role of the NAc shell in the cognitive control over appetitive behavior (Ito and Hayen, 2011). Collectively, the evidence agrees with the hypothesis that NAc shell circuitry integrates telencephalic afferent information with appetitive motivational states and processes to optimize, stabilize, or recover cognitive performance in response to changing stimulus conditions, variations in performance outcome, specifically reward loss (Ambroggi et al., 2011), or competing cognitive operations.

As pointed out in the Results, it was technically infeasible to monitor levels of cholinergic neurotransmission during dSAT performance and simultaneously conduct bilateral infusions into the NAc. However, the evidence is consistent with the conclusion that augmented increases in cholinergic neurotransmission mediated the attenuation of the distractor effect on perfor- mance. First, partial removal of cholinergic projections to prefrontal or parietal regions abolished the enhancement of dSAT performance by NAc shell NMDA infusions. Second, our results suggest that higher levels of cholinergic neurotransmission protect more efficaciously against the effects of the distractor. NAc NMDA stimulation increases basal ACh release by $\sim 150 \%$ (Zmarowski et al., 2005, 2007). Assuming an additive interaction between this effect and the distractor-evoked increase in cholinergic neurotransmission $(\sim 70 \%$ over t1) (Fig. $1 \mathrm{~h})$, cholinergic neurotransmission in dSAT performing animals and following NAc shell NMDA infusions would approach levels that, as suggested by the relationship between release levels and performance (Fig. 1i), attenuate the impact of distractors.

The relationship between increases in cholinergic neurotransmission and the severity of the performance effects of the distractor also rejects the possibility that the distractor stimulus per se increased cholinergic activity. This is also supported by evidence from our prior studies indicating that the presentation of such a stimulus to animals performing noncognitive operant procedures does not increase cortical ACh release. Likewise, reward loss in such situations remained without effect on cortical cholinergic neurotransmission (Himmelheber et al., 1997).

Concerning postsynaptic cholinergic mechanisms, increases in tonic cholinergic activity enhances attention primarily by stimulating nicotinic acetylcholine receptors (NAchRs), specifically $\alpha 4 \beta 2^{*}$ NAchRs expressed by thalamic glutamatergic afferents (Parikh et al., 2008, 2010). Increased cholinergic modulation of cueevoked glutamatergic activity enhances the likelihood for detection of the target stimulus (Howe and Sarter, 2010; Hasselmo and Sarter, 2011). Accordingly, stimulation of $\alpha 4 \beta 2^{\star}$ NAchRs selectively enhances dSAT performance (Howe et al., 2010). The effects of enhanced cholinergic activity via muscarinic receptors are less well understood, in part because of the absence of selective receptor ligands. However, prefrontal stimulation of muscarinic receptors influences cholinergic activity in other cortical regions (Nelson et al., 2005), suggesting that levels of prefrontal cholinergic activity influence the top-down signal to mesolimbic-basal forebrain regions (Newman and McGaughy, 2008).

The present data suggest that the cholinergic modulation of cortical circuitry is not limited to the prefrontal cortex and includes posterior parietal regions. Consistent with this finding, neurophysiological recordings in dSAT performing animals indicated that removal of cholinergic input diminished the overall involvement of both prefrontal and parietal neurons in dSAT performance, with only relatively subtle regional differences between neurons activated by specific trial types or in association with trial outcome (Gill et al., 2000; Broussard et al., 2009). Cho- 
linergic neurotransmission may support overlapping and complementary cognitive operations in prefrontal and parietal regions (Bucci et al., 1998; Thompson and Duncan, 2009), perhaps by enhancing the binding of the multiple features that constitute target stimuli and distractors, respectively (Botly and De Rosa, 2009).

Inattention, impulsivity, and heightened sensitivity to distractors are hallmarks of attention-deficit/hyperactivity disorder and the attentional impairments of patients with schizophrenia, and they have been considered a consequence of deficient top-down control mechanisms (Nuechterlein et al., 2009; Friedman-Hill et al., 2010). Furthermore, attentional symptoms have been linked to dysregulation in motivational systems, specifically mesolimbic glutamatergic-dopaminergic interactions (Cardinal et al., 2001; Alexander et al., 2009; Uchida et al., 2009; Barch and Dowd, 2010; Volkow et al., 2010). As psychostimulants have been hypothesized to alter the dopaminergic modulation of NAc glutamatergic afferents from the cortex (Kalivas, 2007; Rahman and Bardo, 2008), the present evidence provides an explanatory framework for the enhancement of attention by psychostimulants (Pietrzak et al., 2010; Swanson et al., 2010) and by agonists at $\alpha 4 \beta 2^{\star}$ NAchRs (Wilens and Decker, 2007; Radek et al., 2010). Our results define a mesolimbic-basal forebrain cortical system that mediates the motivated activation of attentional mechanisms. Strategies designed to treat attentional impairments or enhance attentional performance may benefit from adopting broader concepts that integrate motivational-attentional interactions and from exploiting the multiple targets known to influence mesolimbic-basal forebrain circuitry.

\section{References}

Adcock RA, Thangavel A, Whitfield-Gabrieli S, Knutson B, Gabrieli JD (2006) Reward-motivated learning: mesolimbic activation precedes memory formation. Neuron 50:507-517.

Alexander KS, Brooks JM, Sarter M, Bruno JP (2009) Disruption of mesolimbic regulation of prefrontal cholinergic transmission in an animal model of schizophrenia and normalization by chronic clozapine treatment. Neuropsychopharmacology 34:2710-2720.

Allen TA, Narayanan NS, Kholodar-Smith DB, Zhao Y, Laubach M, Brown TH (2008) Imaging the spread of reversible brain inactivations using fluorescent muscimol. J Neurosci Methods 171:30-38.

Ambroggi F, Ghazizadeh A, Nicola SM, Fields HL (2011) Roles of nucleus accumbens core and shell in incentive-cue responding and behavioral inhibition. J Neurosci 31:6820-6830.

Barch DM, Dowd EC (2010) Goal representations and motivational drive in schizophrenia: the role of prefrontal-striatal interactions. Schizophr Bull 36:919-934.

Botly LC, De Rosa E (2009) Cholinergic deafferentation of the neocortex using 192 IgG-saporin impairs feature binding in rats. J Neurosci 29:4120-4130.

Bowman EM, Brown VJ (1998) Effects of excitotoxic lesions of the rat ventral striatum on the perception of reward cost. Exp Brain Res 123:439-448

Brooks JM, Sarter M, Bruno JP (2007) D2-like receptors in nucleus accumbens negatively modulate acetylcholine release in prefrontal cortex. Neuropharmacology 53:455-463.

Broussard J, Sarter M, Givens B (2006) Neuronal correlates of signal detection in the posterior parietal cortex of rats performing a sustained attention task. Neuroscience 143:407-417.

Broussard JI, Karelina K, Sarter M, Givens B (2009) Cholinergic optimization of cue-evoked parietal activity during challenged attentional performance. Eur J Neurosci 29:1711-1722.

Bucci DJ, Holland PC, Gallagher M (1998) Removal of cholinergic input to rat posterior parietal cortex disrupts incremental processing of conditioned stimuli. J Neurosci 18:8038-8046.

Cardinal RN, Pennicott DR, Sugathapala CL, Robbins TW, Everitt BJ (2001) Impulsive choice induced in rats by lesions of the nucleus accumbens core. Science 292:2499-2501.
Christakou A, Robbins TW, Everitt BJ (2004) Prefrontal cortical-ventral striatal interactions involved in affective modulation of attentional performance: implications for corticostriatal circuit function. J Neurosci 24:773-780.

Cooper JC, Knutson B (2008) Valence and salience contribute to nucleus accumbens activation. Neuroimage 39:538-547.

Daniel R, Pollmann S (2010) Comparing the neural basis of monetary reward and cognitive feedback during information-integration category learning. J Neurosci 30:47-55.

Demeter E, Sarter M, Lustig C (2008) Rats and humans paying attention: cross-species task development for translational research. Neuropsychology 22:787-799.

Demeter E, Hernandez-Garcia L, Sarter M, Lustig C (2011) Challenges to attention: a continuous arterial spin labeling (ASL) study of the effects of distraction on sustained attention. Neuroimage 54:1518-1529.

Echo JA, Lamonte N, Christian G, Znamensky V, Ackerman TF, Bodnar RJ (2001) Excitatory amino acid receptor subtype agonists induce feeding in the nucleus accumbens shell in rats: opioid antagonist actions and interactions with mu-opioid agonists. Brain Res 921:86-97.

Engelmann JB, Pessoa L (2007) Motivation sharpens exogenous spatial attention. Emotion 7:668-674.

Faure A, Richard JM, Berridge KC (2010) Desire and dread from the nucleus accumbens: cortical glutamate and subcortical GABA differentially generate motivation and hedonic impact in the rat. PLoS One 5:e11223.

Frey PW, Colliver JA (1973) Sensitivity and responsivity measures for discrimination learning. Learn Motiv 4:327-342.

Friedman-Hill SR, Wagman MR, Gex SE, Pine DS, Leibenluft E, Ungerleider LG (2010) What does distractibility in ADHD reveal about mechanisms for top-down attentional control? Cognition 115:93-103.

Gill TM, Sarter M, Givens B (2000) Sustained visual attention performanceassociated prefrontal neuronal activity: evidence for cholinergic modulation. J Neurosci 20:4745-4757.

Greenwald AG, Gonzalez R, Harris RJ, Guthrie D (1996) Effect sizes and $p$ values: what should be reported and what should be replicated? Psychophysiology 33:175-183.

Gruber AJ, Hussain RJ, O’Donnell P (2009) The nucleus accumbens: a switchboard for goal-directed behaviors. PLoS One 4:e5062.

Hasselmo ME, Sarter M (2011) Modes and models of forebrain cholinergic neuromodulation of cognition. Neuropsychopharmacology 36:52-73.

Heckers S, Ohtake T, Wiley RG, Lappi DA, Geula C, Mesulam MM (1994) Complete and selective cholinergic denervation of rat neocortex and hippocampus but not amygdala by an immunotoxin against the p75 NGF receptor. J Neurosci 14:1271-1289.

Himmelheber AM, Sarter M, Bruno JP (1997) Operant performance and cortical acetylcholine release: role of response rate, reward density, and non-contingent stimuli. Brain Res Cogn Brain Res 6:23-36.

Himmelheber AM, Bruno JP, Sarter M (2000) Effects of intra-accumbens infusions of amphetamine or cis-flupenthixol on sustained attention performance in rats. Behav Brain Res 116:123-133.

Holley LA, Wiley RG, Lappi DA, Sarter M (1994) Cortical cholinergic deafferentation following the intracortical infusion of 192 IgG-saporin: a quantitative histochemical study. Brain Res 663:277-286.

Holley LA, Turchi J, Apple C, Sarter M (1995) Dissociation between the attentional effects of infusions of a benzodiazepine receptor agonist and an inverse agonist into the basal forebrain. Psychopharmacology (Berl) 120:99-108.

Howe WM, Sarter M (2010) Prefrontal glutamatergic-cholinergic interactions for attention: glutamatergic coding of salience as a function of performance levels. In: Monitoring molecules in neuroscience (Westerink BHC, Clinckers R, Smolders S, Sarre E, Michotte Y, eds), pp 57-59. Brussels: Vrije Universiteit Brussels.

Howe WM, Ji J, Parikh V, Williams S, Mocaër E, Trocmé-Thibierge C, Sarter M (2010) Enhancement of attentional performance by selective stimulation of alpha4beta2 $\left(^{*}\right)$ NAchRs: underlying cholinergic mechanisms. Neuropsychopharmacology 35:1391-1401

Ingham CA, Bolam JP, Smith AD (1988) GABA-immunoreactive synaptic boutons in the rat basal forebrain: comparison of neurons that project to the neocortex with pallidosubthalamic neurons. J Comp Neurol 273:263-282.

Ito R, Hayen A (2011) Opposing roles of nucleus accumbens core and shell dopamine in the modulation of limbic information processing. J Neurosci 31:6001-6007. 
Kalivas PW (2007) Cocaine and amphetamine-like psychostimulants: neurocircuitry and glutamate neuroplasticity. Dialogues Clin Neurosci 9:389-397.

Knutson B, Adams CM, Fong GW, Hommer D (2001) Anticipation of increasing monetary reward selectively recruits nucleus accumbens. J Neurosci 21:RC159.

Kozak R, Bruno JP, Sarter M (2006) Augmented prefrontal acetylcholine release during challenged attentional performance. Cereb Cortex 16:9-17.

Lim J, Wu WC, Wang J, Detre JA, Dinges DF, Rao H (2010) Imaging brain fatigue from sustained mental workload: an ASL perfusion study of the time-on-task effect. Neuroimage 49:3426-3435.

McGaughy J, Sarter M (1995) Behavioral vigilance in rats: task validation and effects of age, amphetamine, and benzodiazepine receptor ligands. Psychopharmacology (Berl) 117:340-357.

McGaughy J, Dalley JW, Morrison CH, Everitt BJ, Robbins TW (2002) Selective behavioral and neurochemical effects of cholinergic lesions produced by intrabasalis infusions of 192 IgG-saporin on attentional performance in a five-choice serial reaction time task. J Neurosci 22:1905-1913.

Mogenson GJ, Jones DL, Yim CY (1980) From motivation to action: functional interface between the limbic system and the motor system. Prog Neurobiol 14:69-97.

Neigh GN, Arnold HM, Rabenstein RL, Sarter M, Bruno JP (2004) Neuronal activity in the nucleus accumbens is necessary for performancerelated increases in cortical acetylcholine release. Neuroscience 123:635-645.

Nelson CL, Sarter M, Bruno JP (2005) Prefrontal cortical modulation of acetylcholine release in posterior parietal cortex. Neuroscience 132:347-359.

Newman LA, McGaughy J (2008) Cholinergic deafferentation of prefrontal cortex increases sensitivity to cross-modal distractors during a sustained attention task. J Neurosci 28:2642-2650.

Nuechterlein KH, Luck SJ, Lustig C, Sarter M (2009) CNTRICS final task selection: control of attention. Schizophr Bull 35:182-196.

Parikh V, Sarter M (2006) Cortical choline transporter function measured in vivo using choline-sensitive microelectrodes: clearance of endogenous and exogenous choline and effects of removal of cholinergic terminals. J Neurochem 97:488-503.

Parikh V, Kozak R, MartinezV, Sarter M (2007) Prefrontal acetylcholine release controls cue detection on multiple timescales. Neuron 56:141-154.

Parikh V, Man K, Decker MW, Sarter M (2008) Glutamatergic contributions to nicotinic acetylcholine receptor agonist-evoked cholinergic transients in the prefrontal cortex. J Neurosci 28:3769-3780.

Parikh V, Ji J, Decker MW, Sarter M (2010) Prefrontal beta2 subunitcontaining and alpha7 nicotinic acetylcholine receptors differentially control glutamatergic and cholinergic signaling. J Neurosci 30:3518-3530.

Pezze MA, Dalley JW, Robbins TW (2007) Differential roles of dopamine D1 and D2 receptors in the nucleus accumbens in attentional performance on the five-choice serial reaction time task. Neuropsychopharmacology 32:273-283.

Pietrzak RH, Snyder PJ, Maruff P (2010) Use of an acute challenge with D-amphetamine to model cognitive improvement in chronic schizophrenia. Hum Psychopharmacol 25:353-358.

Ptak R, Schnider A (2010) The dorsal attention network mediates orienting toward behaviorally relevant stimuli in spatial neglect. J Neurosci 30:12557-12565.

Radek RJ, Kohlhaas KL, Rueter LE, Mohler EG (2010) Treating the cognitive deficits of schizophrenia with alpha4beta2 neuronal nicotinic receptor agonists. Curr Pharm Des 16:309-322.

Rahman S, Bardo MT (2008) Environmental enrichment increases amphetamine-induced glutamate neurotransmission in the nucleus accumbens: a neurochemical study. Brain Res 1197:40-46.

Ross RS, McGaughy J, Eichenbaum H (2005) Acetylcholine in the orbito- frontal cortex is necessary for the acquisition of a socially transmitted food preference. Learn Mem 12:302-306.

Rossato JI, Bevilaqua LR, Izquierdo I, Medina JH, Cammarota M (2009) Dopamine controls persistence of long-term memory storage. Science 325:1017-1020.

Sabatinelli D, Bradley MM, Lang PJ, Costa VD, Versace F (2007) Pleasure rather than salience activates human nucleus accumbens and medial prefrontal cortex. J Neurophysiol 98:1374-1379.

Salamone JD, Correa M (2002) Motivational views of reinforcement: implications for understanding the behavioral functions of nucleus accumbens dopamine. Behav Brain Res 137:3-25.

Sarter M, Gehring WJ, Kozak R (2006) More attention must be paid: the neurobiology of attentional effort. Brain Res Rev 51:145-160.

Savine AC, Braver TS (2010) Motivated cognitive control: reward incentives modulate preparatory neural activity during task-switching. J Neurosci 30:10294-10305.

Stichel CC, Singer W (1987) Quantitative analysis of the choline acetyltransferase-immunoreactive axonal network in the cat primary visual cortex: I. Adult cats. J Comp Neurol 258:91-98.

Stratford TR, Swanson CJ, Kelley A (1998) Specific changes in food intake elicited by blockade or activation of glutamate receptors in the nucleus accumbens shell. Behav Brain Res 93:43-50.

Swanson J, Baler RD, Volkow ND (2010) Understanding the effects of stimulant medications on cognition in individuals with attention-deficit hyperactivity disorder: a decade of progress. Neuropsychopharmacology $36: 207-226$

Thompson R, Duncan J (2009) Attentional modulation of stimulus representation in human fronto-parietal cortex. Neuroimage 48:436-448.

Uchida H, Rajji TK, Mulsant BH, Kapur S, Pollock BG, Graff-Guerrero A, Menon M, Mamo DC (2009) D2 receptor blockade by risperidone correlates with attention deficits in late-life schizophrenia. J Clin Psychopharmacol 29:571-575.

Volkow ND, Wang GJ, Newcorn JH, Kollins SH, Wigal TL, Telang F, Fowler JS, Goldstein RZ, Klein N, Logan J, Wong C, Swanson JM (2010) Motivation deficit in ADHD is associated with dysfunction of the dopamine reward pathway. Mol Psychiatry. Advance online publication. Retrieved June 9, 2011. doi:10.1038/mp.2010.97.

von Engelhardt J, Eliava M, Meyer AH, Rozov A, Monyer H (2007) Functional characterization of intrinsic cholinergic interneurons in the cortex. J Neurosci 27:5633-5642.

Wager TD, Jonides J, Reading S (2004) Neuroimaging studies of shifting attention: a meta-analysis. Neuroimage 22:1679-1693.

Weissenborn R, Blaha CD, Winn P, Phillips AG (1996) Schedule-induced polydipsia and the nucleus accumbens: electrochemical measurements of dopamine efflux and effects of excitotoxic lesions in the core. Behav Brain Res 75:147-158.

Wilens TE, Decker MW (2007) Neuronal nicotinic receptor agonists for the treatment of attention-deficit/hyperactivity disorder: focus on cognition. Biochem Pharmacol 74:1212-1223.

Záborszky L, Cullinan WE (1992) Projections from the nucleus accumbens to cholinergic neurons of the ventral pallidum: a correlated light and electron microscopic double-immunolabeling study in rat. Brain Res 570:92-101.

Záborszky L, Heimer L, Eckenstein F, Leranth C (1986) GABAergic input to cholinergic forebrain neurons: an ultrastructural study using retrograde tracing of HRP and double immunolabeling. J Comp Neurol 250:282-295.

Zmarowski A, Sarter M, Bruno JP (2005) NMDA and dopamine interactions in the nucleus accumbens modulate cortical acetylcholine release. Eur J Neurosci 22:1731-1740.

Zmarowski A, Sarter M, Bruno JP (2007) Glutamate receptors in nucleus accumbens mediate regionally selective increases in cortical acetylcholine release. Synapse 61:115-123. 